\title{
MENGGAGAS PENDIDIKAN MASA DEPAN
}

Oleh: Triyono ${ }^{1}$

\begin{abstract}
Abstrak
Empat gagasan tentang pendidikan masa depan yang diusulkan sebagai bahan renungan dan diskusi bersama adalah (1) sistem pendidikan di Indonesia seharusnya dibangun berdasarkan falsafah dan budaya bangsa Indonesia sendiri; jika mengadopsi pendidikan dari negara lain, perlu dikaji penerapannya agar sesuai dengan latar belakang budaya masyarakat Indonesia; (2) lembaga pendidikan yang diselenggarakan oleh pemerintah maupun oleh masyarakat idealnya berbentuk badan hukum, sehingga peningkatan kualitas pendidikan dapat dilakukan secara leluasa sesuai dengan jiwa otonomi sekolah; (3) sistem pendidikan di Indonesia perlu diganti dari multitrack menjadi single-track, yang berarti keberadaan SMK perlu diganti dengan lembaga pendidikan vokasional; dan (4) biaya pendidikan di Indonesia mestinya tidak mahal, khususnya bagi masyarakat miskin; untuk jenjang SD/MI dan SLTP/MTS seharusnya gratis.
\end{abstract}

Kata kunci: sistem pendidikan, lembaga pendidikan, berbadan hukum, biaya pendidikan, pendidikan gratis

\section{Pendahluan}

Assalamu 'alaikum wr. wb.

Salam sejahtera untuk kita semua

Yth. Bapak Gubernur beserta unsur Muspida provinsi K alimantan Tengah,

Yth. Bapak Ketua DPRD provinsi Kalimantan Tengah,

Yth. Bapak Walikota beserta unsur Muspida Kota Palangkaraya,

Yth. Bapak Rektor selaku Ketua Senat Universitas Palangkaraya,

Yth. Para anggota Senat Universitas Palangkaraya,

Yth. Para Kepala Dinas, Badan, dan Perangkat Daerah provinsi Kalimantan Tengah,

${ }^{1}$ Dosen Tetap FKIP Universitas Palangkaraya 
Yth. Para wisudawan beserta keluarganya,

Para undangan dan hadirin yang berbahagia

Sebelum menyampaikan pidato ilmiah, izinkanlah saya mengucapkan Selamat Hari Raya Idul Fitri, 1 Syawal 1424 H., bagi yang merayakannya. Minal 'aidin walfaidzin, mohon maaf lahir dan batin. Saya juga mengucapkan selamat merayakan hari Natal dan Tahun Baru 2004, yang sebentar lagi akan kita lalui.

Sungguh merupakan kebahagiaan bagi saya sekeluarga, karena pada hari ini saya dikukuhkan menjadi Guru Besar di universitas yang kita cintai ini. Selanjutnya, melalui mimbar ini saya ingin menyampaikan penghargaan dan terima kasih yang setulus-tulusnya kepada:

1. Bapak dan ibu guru saya di SDN-2 Ngaran, Polanharjo, Kabupaten Klaten,

2. Bapak dan ibu guru saya di SMPN-1 Polanharjo, Kabupaten Klaten,

3. Bapak dan ibu guru saya di STM Muhammadiyah-1 Klaten,

4. Bapak, ibu dosen dan guru besar saya di FKIP Universitas Palangkaraya,

5. Bapak, ibu dosen dan guru besar saya di Universitas Sebelas Maret Surakarta,

6. Bapak, ibu dosen dan guru besar saya di Universitas Negeri Yogyakarta,

7. Bapak, ibu dosen dan guru besar saya di Universitas Negeri Jakarta

yang telah mengajarkan saya dari membaca dan menulis sampai membuka cakrawala berpikir, mengembangkan wawasan, serta membimbing dan mengarahkan saya hingga mencapai jabatan akademik tertinggi yang saya terima pada hari ini.

Sujud dan bakti dipersembahkan kepada kedua orangtua saya yang telah tiada, diiringi doa semoga semua pengorbanan yang beliau curahkan untuk anak-anaknya memperoleh pahala dari Tuhan Yang Mahakuasa.

Atas kesabaran dan ketabahan istri dan anak-anak saya selama mendampingi saya, --baik suka dan duka--, terlebih di saat saya menempuh pendidikan di Yogyakarta dan Jakarta, saya ucapkan terima kasih. 
Dalam mengawali tugas memangku jabatan ini, saya mengajak hadirin sekalian untuk mencermati masalah pendidikan di negara kita. Membicarakan masalah pendidikan sepertinya tidak pernah ada habisnya, sebab semua orang berkepentingan terhadap pendidikan.

Orientasi pendidikan suatu bangsa akan menunjukkan bagaimana praktik pendidikan berlangsung dan pada tahap berikutnya dapat dijadikan dasar untuk memprediksi kualitas lulusan yang dihasilkan. Menurut Zamroni (2001) setiap orientasi pendidikan dapat dikaji dari empat dimensi, yaitu: status siswa, peran guru, materi pembelajaran, dan manajemen pendidikan.

Dimensi status siswa, terentang dari siswa sebagai objek dan siswa sebagai subjek. Dimensi peran guru, tersebar dari guru sebagai pemegang otoritas dan fungsi guru sebagai fasilitator dalam proses pembelajaran. Dimensi materi pembelajaran, memiliki rentang dari materi sebagai subject-oriented sampai pada materi sebagai problem-oriented. Dimensi manajemen pendidikan, terentang dari manajemen sentralistik dan manajemen berbasis sekolah (school-based-management).

Orientasi pendidikan di Indonesia selama ini cenderung memperlakukan siswa sebagai objek, guru berfungsi sebagai pemegang otoritas tertinggi, materi pembelajaran bersifat subject-oriented, dengan manajemen yang dikendalikan secara sentralistik. Hal tersebut menjadikan pendidikan di Indonesia mengisolasi diri dari kehidupan riil yang ada di luar sekolah, apa yang dipelajari kurang relevan dengan kebutuhan dalam pekerjaan, serta terkonsentrasi pada pengembangan intelektual. Proses pembelajaran yang terjadi, didominasi oleh tuntutan untuk menghafal dan menguasai bahan pelajaran sebanyak mungkin dalam rangka menghadapi ujian.

Akibat dari praktik pendidikan semacam itu, muncul berbagai kesenjangan akademik, kesenjangan okupasional, dan kesenjangan kultural. Kesenjangan akademik dapat dilihat dari ilmu yang dipelajari siswa kurang terkait dengan kehidupan sehari-hari. Hal ini disebabkan antara lain guru tidak mampu mengkaitkan 
bahan pelajaran dengan fenomena sosial yang terjadi dalam masyarakat. Kesenjangan okupasional tampak dari jauhnya dunia pendidikan dengan dunia kerja; sedangkan kesenjangan kultural diindikasikan oleh ketidakmampuan siswa dalam memahami masalah-masalah yang sedang dan akan dihadapi oleh bangsanya di masa depan.

Jika kualitas sumberdaya manusia Indonesia dihasilkan melalui proses pendidikan sebagaimana yang saya kemukakan di atas, bangsa kita akan mengalami kesulitan dalam menghadapi tantangan-tantangan yang muncul sebagai akibat adanya kecenderungan global. Oleh karena itu, pembaharuan dan reformasi sistem pendidikan secara total merupakan suatu keharusan yang tidak bisa ditunda.

\section{Kiblat Pendidikan}

Di sekolah kita saat ini sedang gencar dilakukan sosialisasi Kurikulum Berbasis Komptensi (KBK), pendidikan berbasis luas (broad-based-education) melalui pendidikan yang berorientasi pada kecakapan hidup (life-skill education). Sekolahsekolah disediakan sejumlah dana yang bersumber dari Program Kompensasi Pengurangan Subsidi (PKPS) BBM; untuk diperebutkan secara "kompetisi". Akibatnya sekolah-sekolah kita sekarang dilanda semangat untuk menerapkan sistem pengajaran yang menekankan proses pembelajaran melalui berbagai pendekatan seperti: CTL (Contextual Teaching and Learning), RME (Realistic Mathematic Education), AJEL (Active, Joyfull, and Effective Learning). Pendekatan ini diyakini dapat meningkatkan proses dan hasil belajar siswa yang diperoleh dengan cara mengkonstruksi pengetahuan dan pengalamannya sendiri. Sejak tahun 2002 para guru dan dosen FKIP dilatih sebagai TOT (training of trainer) dan dilanjutkan dengan pelatihan di daerah. Diakui bahwa, pendekatan tersebut sangat baik untuk meningkatkan kemampuan berpikir kritis siswa; akan tetapi dalam praktiknya sulit diterapkan di Indonesia. Sebab untuk menerapkan metode ini, peserta didik dituntut 
harus memiliki semangat untuk mencari kebenaran dan keberanian dalam mengutarakan pendapat; yang belum dimiliki oleh siswa-siswa di Indonesia.

Di perguruan tinggi juga ditawarkan program DUE-like (Development for Undergraduate Education), Semi-QUE, QUE-like (Quality for Undergraduate Education), TPSDP (Technical and Professional Skill Development Program ) dan Program Hibah Kompetisi A-1, A-2, dan B. Program-program tersebut juga diimpor dari negara-negara industri maju.

Pertanyaan yang muncul di benak saya adalah Apakah benar kesuksesan program pendidikan di negara lain dapat dipindahkan ke negara kita? Menurut pendapat saya, (1) sistem pendidikan di Indonesia harus sesuai dengan falsafah dan budaya bangsa Indonesai sendiri, dan (2) mengadopsi suatu gagasan pendidikan dari negara lain harus dikaji penerapannya agar sesuai dengan latar belakang budaya masyarakat Indonesia. Kita bisa saja meniru orang lain yang sukses sebagai peternak; tetapi apakah kita juga akan sukses seperti peternak yang kita ikuti tadi?

\section{Lembaga Pendidikan sebagai Badan Hukum}

Pendidikan bukan hal yang mudah dan sederhana. Proses pendidikan bukan sebuah pabrik yang jika tombol ditekan, maka semua proses akan berjalan teratur sebagaimana yang diprogramkan. Selain sifatnya yang kompleks, dimanis, dan kontekstual; pendidikan merupakan wacana yang melibatkan pembentukan aspek kognitif, psikomotorik; bahkan aspek afeksi dan pembentukan diri seseorang secara keseluruhan. Aspek-aspek tersebut, secara rinci dibahas oleh Fullan (1985) sebagai tujuan umum pendidikan, di mana aspek kognitif meliputi keterampilan akademik membaca, menulis, dan berhitung-dan keterampilan berpikir yang tinggi untuk memecahkan masalah. Pendidikan harus pula melibatkan tujuan pengembangan aspek pribadi dan sosial yang memungkinkan peserta didik mampu bekerja sama dan hidup dalam kelompok secara kreatif, inisiatif, empatik, dan memiliki keterampilan interpretasi yang memadai. 
Harus diakui bahwa selama ini sekolah-sekolah kita dikontrol secara ketat oleh pusat, sehingga tidak memiliki keleluasaan untuk mengelola sumberdaya dalam upaya meningkatkan kualitas pendidikan. Agar lebih terjamin makin rendahnya kontrol pemerintah pusat dan makin meningkatnya otonomi sekolah dalam menentukan sendiri apa yang perlu diajarkan dan cara mengelola sumberdaya dalam berinovasi, maka manajemen pendidikan perlu diserahkan pada sekolah. Manajemen pendidikan berbasis sekolah pada dasarnya bertumpu pada sekolah dan masyarakat serta jauh dari birokrasi yang sentralistik (Jalal dan Supriadi, 2001; Wangid, 2000). Otonomi pendidikan harus pula dimaknai sebagai kesempatan bagi guru untuk mengembangkan prakarsa dan kreativitas dengan melibatkan siswa untuk belajar bagi dirinya sendiri. Dalam manajemen berbasis sekolah, kepala sekolah dan guru memiliki kebebasan yang luas dalam mengelola sekolah tanpa mengabaikan kebijakan pemerintah. Fungsi manajemen sekolah mencakup (1) manajemen kepemimpinan, (2) proses pembelajaran, (3) sumberdaya manusia, dan (4) administrasi sekolah. Manajemen berbasis sekolah hanya terlaksana dengan baik, jika lembaga pendidikan baik yang diselenggarakan oleh pemerintah maupun oleh masyarakat berbentuk badan hukum. Apabila lembaga pendidikan berbentuk badan hukum, pengembangan kualitas pendidikan dapat dilakukan secara leluasa. Dana pendidikan juga harus langsung diterima oleh sekolah tanpa melalui jalur birokrasi yang panjang. Dalam hal ini, Badan Akreditasi Sekolah perlu diberikan kewenangan untuk mengontrol, mengendalikan, dan menjamin kualitas proses dan hasil pendidikan.

\section{Hapuskan Sekolah Menengah Kejuruan}

Sejak bangsa ini merdeka hingga sekarang, telah beberapa kali melakukan pembaharuan pendidikan, namun sifatnya hanya tambal-sulam. Pembaharuan pendidikan secara mendasar dan total yang menyentuh pada sistem pendidikan belum pernah dilakukan. Sistem pendidikan yang diberlakukan di Indonesia selama 
ini adalah sistem multi-track, artinya pada jenjang Sekolah Dasar hanya ada satu jenis pendidikan (umum), sedangkan pada jenjang Sekolah Lanjutan Tingkat Pertama dan Sekolah Menengah Tingkat Atas ada beberapa jenis pendidikan (umum dan kejuruan). Tentunya kita masih ingat, sekitar tahun 1970-an di tingkat SLTP ada SMP, ST, SMEP, SKKP; dan di tingkat SLTA ada SMA, SMEA, SMPS, STM, SKKA, SMOA, SMPT, SMIK, dll.

Kurikulum pendidikan di SMK, katanya dirancang agar lulusannya "siap pakai". Ini berarti lulusan SMK mestinya memiliki keterampilan tertentu dan siap memasuki dunia kerja atau sebagai bekal hidup dalam masyarakat. Tetapi apakah benar lulusan SMK kita sekarang siap pakai?

Kita mengetahui bahwa hampir semua pembaharuan pendidikan di negara ini dijiplak dari negara-negara industri maju; padahal Indonesia bukanlah negara industri. Sebagai contoh, Pendidikan Sistem Ganda (PSG) yang diterapkan di SMK melalui sistem magang, diadopsi dari pendidikan di Jerman Barat. Di negara asalnya, pelaksanaan dual-system di SMK dilakukan di perusahaan-perusahaan sesuai dengan bidangnya sehingga siswa SMK benar-benar memperoleh pengalaman kerja yang optimal dan dapat dijadikan bekal untuk memasuki dunia kerja atau bekal hidup dalam masyarakat. Tetapi pelaksanaan sistem magang bagi siswa SMK di Indonesia ditempatkan di kantor-kantor pemerintah dan di took-toko. Pengalaman apa yang mereka peroleh?

Menurut pemikiran saya, SMK perlu dihapuskan dan sistem pendidikan diganti dari multi-track menjadi single-track. Alasannya adalah (1) sekolah hanya dapat memberi pelajaran yang bersifat teori (Reimer, 2000), sehingga (2) bekal keterampilan sebaiknya diserahkan kepada Lembaga Pendidikan Vokasional. Sistem pendidikan single-track yang saya usulkan tersebut adalah:

1. Pada jenjang Pendidikan Dasar (9 tahun), terdiri dari 6 tahun di SD/MI dan 3 tahun di SLTP/MTs. 
2. Pada jenjang Pendidikan Menengah (3 tahun), hanya ada SMU/MA (sekolah umum) dan SMK dihapuskan.

3. Pada jenjang pendidikan tinggi (4-6 tahun), baru disediakan berbagai pilihan jurusan atau program studi.

4. Untuk menyediakan tenaga terampil tingkat menengah, dibentuklah Lembaga Pendidikan Vokasional (1-2 tahun) yang secara khusus diserahi tugas memberikan bekal "keterampilan" tertentu sesuai dengan kebutuhan masyarakat dan dunia kerja. Kurikulum di Lembaga Pendidikan Vokasional ini hanya memuat $20 \%$ teori yang secara nyata terkait dengan keterampilan serta $80 \%$ praktik dan magang. Sebagai tanda bukti keterampilan yang dimiliki peserta didik Lembaga Pendidikan Vokasional, mereka yang lulus uji kompetensi.

\section{Biaya Pendidikan yang Murah}

Bangsa Indonesia telah merdeka 60 tahun lamanya, tetapi mengapa akhir-akhir ini biaya pendidikan justru makin melangit? Anehnya lagi, bukan hanya di lembaga pendidikan swasta, sekolah-sekolah (termasuk perguruan tinggi negeri) terkesan berlomba-lomba menaikkan biaya pendidikan. Jika biaya pendidikan di lembaga pendidikan swasta menjadi mahal, masih lumrah dan bisa dimaklumi, karena segala biaya yang dibutuhkan harus ditanggung sendiri. Tetapi, jika mahalnya biaya pendidikan juga terjadi di lembaga pendidikan yang diselenggarakan oleh pemerintah, sungguh-sungguh "luar biasa".

Kita semua mengetahui bahwa untuk mensukseskan pelaksanaan program wajib belajar pendidikan dasar sembilan tahun, pemerintah telah membebaskan SPP; akan tetapi jangan diartikan bahwa sekolah di SD/MI dan SLTP/MTs menjadi gratis. Orangtua yang anaknya sekolah di SD/MI dan SLTP/MTs harus mengeluarkan uang yang mungkin jumlahnya lebih tinggi dari SPP. Berbagai label sumbangan, dengan dalih untuk pengembangan pendidikan, yang nilainya bervariasi; bahkan ada biayabiaya "siluman" yang tidak dikenal dalam dunia akademik. Saya pernah mendengar 
selentingan bahwa untuk bisa diterima sebagai mahasiswa di sebuah perguruan tinggi negeri tertentu, konon harus "membeli" kursi hingga puluhan juta rupiah.

Gejala mahalnya biaya pendidikan akhir-akhir ini tidak boleh berlanjut, sebab apabila hal itu terus terjadi, dipastikan pendidikan yang berkualitas dan pendidikan tinggi tertentu, hanya akan dinikmati oleh orang-orang yang memiliki akses ekonomi dan politik yang tinggi, yaitu orang-orang kaya yang berduit, anak-anak pejabat dan konglomerat (Dawam, 2003). Anak-anak "wong cilik" dan masyarakat marginalmeskipun punya kecerdasan yang ruarrr biasa-sulit berharap dapat menikmati pendidikan yang berkualitas dan perguruan tinggi. Pendidikan harus bersifat humanis-populis, dalam arti meletakkan manusia sebagai tujuan dan harus menjangkau semua lapisan masyarakat termasuk mereka yang terpinggirkan (Wahono, 2001).

Padalah, kalau saja benar-benar dilaksanakan minimal 20\% dari APBN dan minimal $20 \%$ dari APBD dialokasikan untuk sektor pendidikan sebagaimana dinyatakan dalam pasal 49 ayat (1) UU Nomor 20 tahun 2003, mestinya sekolah di SD/MI dan SLTP/MTs bisa benar-benar gratis; tanpa ada embel-embel lain. Tetapi, tampaknya kita belum bisa berharap, sebab anggaran pendidikan untuk tahun 2004 mendatang masih berkisar 4-5\% dari ABPN.

\section{Kesimpulan}

Empat gagasan pokok tentang pendidikan masa depan yang saya usulkan sebagai bahan renungan dan diskusi kita bersama adalah Pertama, sistem pendidikan di Indonesia harus dibangun berdasarkan falsafah dan budaya bangsa Indonesia sendiri. Jika mengadopsi gagasan pendidikan dari negara lain, perlu dikaji penerapannya agar sesuai dengan latar belakang budaya masyarakat Indonesia. Kedua, lembaga pendidikan baik yang diselenggarakan oleh pemerintah maupun oleh masyarakat idealnya berbentuk badan hukum, sehingga peningkatan kualitas pendidikan dapat dilakukan secara leluasa sesuai dengan jiwa otonomi sekolah. 
Ketiga, sistem pendidikan kita perlu diganti dari multi-track menjadi single-track, yang berarti keberadaan SMK perlu ditinjau kembali. Lembaga sekolah hanya ditugasi memberikan bekal pengetahuan dan pembentukan sikap dan nilai, sedangkan bekal keterampilan sebaiknya diserahkan kepada lembaga pendidikan vokasional. Keempat, biaya pendidikan di Indonesia mestinya tidak mahal, khususnya bagi masyarakat miskin. Paling tidak, untuk jenjang SD/MI dan SLTP/MTs (negeri) seharusnya gratis; dalam arti orangtua murid tidak lagi dibebani biaya apapun. Jika $20 \%$ dari APBN dan APBD benar-benar dialokasikan untuk sektor pendidikan, bukan mustahil hal ini bisa menjadi kenyataan. Semoga.

\section{Daftar Rujukan}

Dawam, A. (2003). Emoh Sekolah: Menolak Komersialisasi Pendidikan dan Kanibalisme Intelektual, Menuju Pendidikan Multikultural. Yogyakarta: Anspeal Ahimsakarya Press.

Depdiknas. (2003). Undang-Undang Republik Indonesia Nomor 20 Tahun 2003 tentang Sistem Pendidikan Nasional. Jakarta: Depdiknas.

Fullan, M. (1985). "Change Processes and Strategies at Local Level" dalam The Elementary School Journal. Vol. 85 No. 3.

Jalal, F. dan Supriadi, D. (Eds). (2001). Reformasi Pendidikan dalam Konteks Otonomi Daerah. Yogyakarta: Adicita Karya Nusa.

Jhonson, E. B. (2002). Contextual Teaching and Learning: What It is and Why It's Here to?. California: A Sage Publications Co.

Reimer, E. (2000). Matinya Sekolah: Esai tentang Alternatif Pendidikan. Yogyakarta: Hanindita Graha Widia.

Wahono, F. (2001). Kapitalisme Pendidikan: Antara Kompetensi dan Keadilan. Yogyakarta: Insist Press.

Wangid, M. N. (2000). "Peran dan Makna Otonomi Pendidikan bagi Guru" dalam Dinamika Pendidikan. No. 2, Thn VII, 2000. pp. 29-44.

Zamroni. (2001). Paradigma Pendidikan Masa Depan. Yogyakarta: Bigraf Publishing. 